Article

\title{
Does Sustainable Perceived Value Play a Key Role in the Purchase Intention Driven by Product Aesthetics? Taking Smartwatch as an Example
}

\author{
Jian Wang ${ }^{1,2}$ and Yen Hsu ${ }^{1, * \mathbb{D}}$ \\ 1 The Graduate Institute of Design Science, Tatung University, Taipei 10491, Taiwan; \\ wangjian_168@nuaa.edu.cn \\ 2 Jincheng College of Nanjing University of Aeronautics and Astronautics, Nanjing 210000, China \\ * Correspondence: yhsu@gm.ttu.edu.tw; Tel.: +886-21822928-6731
}

Received: 31 October 2019; Accepted: 28 November 2019; Published: 30 November 2019

\begin{abstract}
In the face of a wide range of consumer electronic products, how can consumers take into account the sustainable development of the ecological environment during their purchase and consumption? This study established a new product aesthetics classification, divided it into interface aesthetics and product form aesthetics, and proposed a new conceptual model to test the impact of interface aesthetics and product form aesthetics on sustainable perceived value and purchase intention. In this study, smartwatches were used as the subject and a two-stage survey was carried out to collect samples from common consumers of consumer electronic products. Partial least squares (PLS) was employed to test the conceptual model and corresponding hypotheses on data collected from 425 survey samples. The research results suggested that interface aesthetics and product form aesthetics must be mediated by sustainable perceived value so as to have a positive impact on consumers' purchase intention. Therefore, sustainable perceived value is a mediating variable for adjusting product aesthetics and purchase intention. In addition, sustainable perceived value greatly affects consumers' green consumer behavior. Increasing the emotional durability established between consumers and products through sustainable perceived value to prolong the life of products reduces resource consumption and wave costs, and promotes sustainable development of ecological resources.
\end{abstract}

Keywords: interface aesthetics; product form aesthetics; sustainable perceived value; purchase intention; smartwatch

\section{Introduction}

With the growing importance of high-quality appearances and aesthetic appeal in product design, Jordan (1998) suggested that in addition to usability, sense of security, confidence, pride, and satisfaction, there is also a particular aesthetic pleasure to be provided in product design [1]. Consumer electronics products meet a wide range of needs. In addition to being used to perform tasks, products also fulfill other functional requirements, including expectations, social, and emotional requirements [2]. In the approach to meet those functional requirements, scholars have focused on the nature and development of visual design aesthetics in product form design [3]. The design aesthetics of products is a determinant of market success and failure. An excellent product design attracts the attention of consumers and improves user experience in a bid to enhance the perceived value of products [4].

This study proposed a novel concept, sustainable perceived value, which was derived from the green perceived value and ecological perceived values proposed by previous literature, and was based on consumers' environmental desires, sustainable expectations, and green needs [5,6]. Sustainable perceived value is an ecology-oriented value. Apple, for example, has long prided itself on having 
sustainable values. In addition to focusing on product design aesthetics, the environmentally friendly manner, which emphasizes product materials, is widely shared by consumers. Tim Cook announced, at the Apple Fall 2019 launch, that Apple products use recyclable materials in an all-around manner, thereby enhancing the sustainable production of Apple products. Now, Apple plans to take the concept of sustainable development a step further. To address the environmental impact of electronic component production, it has developed a recycling robot specifically designed to dismantle scrap machines, in the hopes of fully recycling product materials and applying them to its new products. It can be seen that as consumers become more aware of the potential negative effects of consumption on the natural environment, sustainable perceived value is likely to become an important factor affecting the consumption of electronics products.

Currently, many companies have realized that environmental protection issues will attract consumers' attention and may affect their purchasing decisions. Recently, Paul, Modi, and Patel (2016) used the extended Theory of Planned Behavior (TPB) as the theoretical framework for explaining the purchase intention so as to predict the cost of green products [7]. Koller, Floh, and Zauner (2011) study assessed the impact of ecological values on other value dimensions (functional, economic, emotional, and social) in order to understand how ecological aspects of consumer spending fit into the relationship between perceived values and consumer loyalty intentions [6]. This study intends to further understand the role of sustainable perceived value between product aesthetics and purchase intention, and to provide more comprehensive information for sustainable development of the ecological environment. In addition, the sustainable perceived value in this study is related not only to altruism, but to ethical values. Hoover et al. (2018) clarified the relationship between ethical values and charitable donation sensitivity [8]. When making green consumer decisions, such ethical values or charitable donation sentiment will lead consumers to act in an environmentally sound manner rather than neglecting the consequences caused to the environment for the sake of their own benefits. Indeed, product design is closely linked to the concept of sustainable development so as to minimize negative impacts, maximize positive impacts, and achieve a balance of ecology, society, and culture [9]. Current models for many electronically-mediated products continuously update their version, but indeed only make minor improvements to each version [10]. As a result, consumer electronics products are being used more and more frequently and over shorter periods of time, leading to increasingly severe e-waste problems. To respond to such situation, it is of great necessity to reduce resource consumption and the significant environmental concerns and health hazards associated with e-waste. Sustainability involves a number of issues, and focuses on design aesthetics for emotional attachment, thereby creating products that users enjoy, value, and use for longer [10]. Previous researches have shown that emotional perceived value may handle product-user relationships, increase user experience and happiness, and extend product lifecycles [11]. Consumers have strong emotional relations with products due to their services, information, and connotations. Moreover, the functional, social, and emotional value requirements of consumers affect the relationship between consumers and products, and such relationships will lead to more balanced design outcomes and products with a longer shelf life [2].

Aesthetics is viewed as a non-instrumental quality, which forms an important aspect of product attractiveness and experience [12]. A diversified design is needed at the mature stage of product expansion to meet consumer requirements for aesthetics, which may affect the consumers' purchase intention $[13,14]$. From the consumer perspective, this kind of experience plays an important role in determining consumer preferences and then influencing their purchase decisions [15]. In addition, previous studies have shown that perceived value is a vital antecedent and key determinant of purchase intention [15-17]. Researchers have argued that the higher the consumers' perceived value, the stronger their willingness to buy [18]. Therefore, this study held that sustainable perceived value may play a key role between product aesthetics and purchase intention. The relation between product aesthetics and sustainable perceived value can trigger the purchase intention for consumers. In addition, increasing the emotional durability established between consumers and products through sustainable perceived 
value to prolong the life of products reduces resource consumption and wave costs, and promotes sustainable development of ecological resources.

With the increasing number of consumer electronics products in daily life, smart wearable products have become an indispensable part of people's lives, especially smartwatches, which are considered a new type of fashion and technology. Smartwatches are not only a continuation of the smartphone but also the first smart wearable products to be popularized. The salient structural features of smartwatch aesthetics show features of the visual aesthetics of human-computer interfaces and product form aesthetics [19-21]. Therefore, this study attempted to establish a new product design aesthetics classification that divides product aesthetics into interface aesthetics and product form aesthetics. The impact of a smartwatch's product aesthetics on aesthetic perception and the purchase intention of consumers has long been neglected in the sustainable development field. A large number of studies have focused on the technical field of smartwatches, but few have focused on the aesthetics of smartwatches. Previous studies have shown that among the antecedents of smartwatch purchase intention, the design aesthetics of products has a significant impact [16]. Jung et al. (2016) found that the attractiveness of aesthetics has a positive and significant impact on consumer intention to use smartwatches [13]. Based on the results of previous empirical studies, it remains unclear whether smartwatch's aesthetics will affect purchase intention under the influence of sustainable perceived value. In addition, as perceived value is a key predictor of purchase intention of consumers and supplier income, the relationship among product aesthetics, sustainable perceived value, and purchase intention was established to validate the business value of product aesthetics, and more importantly, to fully explore the sustainable development of product aesthetics in the economy, society and environment. Therefore, in order to fill in the aforementioned gaps in research, this study aimed to achieve the following purposes:

- Based on the literature review and the structural features of smartwatches, this study attempted to establish new product aesthetic classifications for interface aesthetics and product form aesthetics. In interface aesthetics, the Visual Aesthetics of Website Inventory (VisAWI) scale was used to evaluate the visual aesthetics of smartwatch human-computer interfaces.

- This study proposed a novel concept known as sustainable perceived value to test the mediating effect of sustainable perceived value on purchase intention driven by product aesthetics.

- This study analyzed product aesthetics based on a literature review. A new conceptual model and corresponding hypotheses were proposed to test the impact of interface aesthetics and product form aesthetics on sustainable perceived value and purchase intention.

\section{Literature Review}

Following a review of the relevant literature, interface aesthetics was found to include four first-order constructs, while product form aesthetics was found to include six first-order constructs. Sustainable perceived value could be divided into three first-order constructs, with the last construct being purchase intention. The main components in each construct are reviewed in the following sections.

\subsection{Interface Aesthetics}

The importance of aesthetics in interface design stems from the findings of Kurosu and Kashimura (1995), which suggest that visually appealing interface designs are more user-friendly [22]. In the context of human-computer interaction or interactive product design, the aesthetics of user interfaces has become a major concern. Such aesthetics are not only visual aesthetics, but also a beautiful experience that interface aesthetics brings to users [20]. Hallnas and Redstrom (2002) held that enhancing interface aesthetics for electronic media devices facilitates a wider range of user acceptance [23]. Kim et al. (2003) analyzed website interfaces, and summarized the general common aesthetic design factors and users' emotional responses towards those factors [24]. Previous studies indicated that mobile interfaces based on visual aesthetics are a perfect combination of content, function, and aesthetics [23,25]. Mobile 
interfaces adopt a combination of design elements such as graphics, text, color, etc., to give users an intuitive feeling. Meanwhile, interface visualization and aesthetic are perceptual and accepted as beauty in the course of the user experience. The visual aesthetics of human-computer interfaces is an important determinant of user satisfaction and happiness [26]. A smartwatch's touch-screen interface design provides greater satisfaction for users when performing information searches, communication, and entertainment activities on their devices.

At present, various aesthetics-related constructs of user interfaces have been identified in empirical studies, including symmetry, diversity, colorfulness, and the visual complexity of user interfaces [27,28]. Lavie and Tractinsky (2004) developed a questionnaire to measure the visual aesthetics of websites interfaces [28]. They indicated that users' subjective aesthetic view of websites contains two main aesthetic aspects, namely, classical aesthetics and expressive aesthetics. Moshagen and Thielsch (2010) introduced another measurement method that encompasses the broader perceptions of interface aesthetics constructs [27]. Their measurement contains 18 items, from which four different aspects of user-centered aesthetic perception are derived: simplicity, diversity, colorfulness, and craftsmanship. Simplicity is closely related to Lavie and Tractinsky's (2004) classical aesthetics, while diversity is closely related to Lavie and Tractinsky's (2004) expressive aesthetics. In addition, Moshagen and Thielsch (2010) created two new discrete facets: colorfulness and craftsmanship [27]. Colorfulness includes constructs related to the evaluation of colors and their components, and craftsmanship reflects the harmonized design of the interface and the use of modern technology [27].

As the boundary between websites and software interfaces tends to shrink, the differences in the layout of human-computer interfaces may become increasingly less important. Therefore, Moshagen and Thielsch $(2010,2013)$ deemed that the structure of interface aesthetics can be reasonably proposed and that the VisAWI scale can be used to evaluate the aesthetics of other human-computer interfaces $[27,29]$, such as smartphone interfaces. The relative constructs of smartwatch interface aesthetics are similar to those of websites. To validate the feasibility and importance of Moshagen and Thielsch's (2010) assessment of visual aesthetics in other human-computer interfaces, the constructs of interface aesthetics in this study referred to the VisAWI scale of Moshagen and Thielsch (2010) [27]. VisAWI captures four different aspects of user perceptions (simplicity, diversity, colorfulness, and craftsmanship). It can precisely measure interface aesthetics, and it is more sensitive to the color-related design aspects of aesthetic perception [30]. The relevant details are described below.

\subsubsection{Simplicity}

Simplicity has been determined to be one of the main constructs that affect visual aesthetical perceptions and is a core factor in early aesthetical perceptions methods [26,30]. Berlyne's (1971) psychological theory on aesthetics illustrates the important relationship between simplicity and complexity [31]. Karvonen (2000) saw simplicity as an aesthetic construct that can act as a link between aesthetics and usability at the perception level [32]. The concept of simplicity in VisAWI and Gestalt physiologists' figural goodness concept includes aspects that facilitate the perception and the processing of a layout [30], such as clarity, homogeneity, order, and balance [27]. Researchers have argued that simplicity is one of the most important qualities in interface aesthetics and that the initial impression of beauty and cleanliness is attributed to high visual fluidity [25,33], because less information may reduce the needed attention. Therefore, people prefer simple interfaces. Simplicity can significantly influence consumer attitude, consumer attention, and purchase intention [34].

\subsubsection{Diversity}

The concept of diversity is related to dynamic, variety, visual abundance, creativity, interest, and novelty. It is an expressive aesthetic construct $[29,30]$. In addition, diversity is closely related to visual complexity. From the user's perspective, the number of interface elements and the diversity of information constitute visual complexities in the interface. Based on the analysis of the relationship 
between visual complexity and aesthetics in previous studies [27], it has been proved that diversity is one of the constructs that affect interface aesthetics.

\subsubsection{Colorfulness}

Colorfulness refers to the evaluation of individual colors, as well as their composition, selection, placement, and combination [27]. Color is widely recognized as one of the most compelling design elements in human-computer interfaces at first sight [30,35]. However, in the field of human-computer interfaces, scanty studies have discussed the effects of color on the perception of aesthetics. In human computer interaction, questionnaires are used to operationalize aesthetic perception and models are established for algorithmic prediction of user interface aesthetics, thus achieving colorfulness [27,28]. Colorfulness is a visual cue that helps consumers form a state of affair with the product interface aesthetics. It plays a leading role in shaping consumers' perceived value with respect to interface aesthetics and is able to arouse consumer sentiment [34].

\subsubsection{Craftsmanship}

Craftsmanship is the skillful and coherent integration of relevant design dimensions [27,30]. It can reflect whether a website's interface has a harmonized design and use of modern technology. Interface design is a rapidly developing field. With the innovation and development of technology, interfaces need to use modern technology to avoid bringing the impression of being outdated to users [26]. Therefore, as one of the constructs of interface aesthetics, craftsmanship has a certain impact on the evaluation of user interface aesthetics.

\subsection{Product form Aesthetics}

Product form aesthetics is a way to get consumer attention and is a means of communicating information to consumers. It creates initial impressions and affects the quality of people's lives. The perception and use of products with aesthetic design can provide sensory pleasure and stimulation. Instead, products with unattractive forms can be bothering [4]. When the price and function of a selected product are the same, consumers will actively consider the product's visual appearance and purchase the product they consider to be more visually attractive [4]. Product form aesthetics is considered a key design factor for communicating with potential consumers and is the primary factor in meeting potential consumers' expectations [21]. Mugge, Dahl, and Schoormans (2018) argue that in cluttered markets, product form aesthetics is a way to capture consumer attention as well as an important means of delivering information to consumers [36].

Swilley (2012) put forward three constructs of product aesthetics: product design, product color, and overall appearance [37]. Among them, the overall appearance is regarded as a second-order construct that includes the three parts of texture/touch, beauty, and shape. Later, Swilley (2012) treated overall appearance as an independent construct for testing and developed a measurement method for six constructs [37]. Toufani, Stanton, and Chikweche (2017) used Swilley's (2012) six constructs of aesthetics in their study of the aesthetics of smartphones [14]. The product form aesthetics in this study used four constructs of aesthetics from Swilley (2012) and Toufani, Stanton, and Chikweche (2017) [14,37], namely, color, texture/touch, shape, and overall appearance. In addition, according to a recent study by Dehghani and Kim (2019) on smartwatches [38], this study added two constructs to the conceptual model, namely, screens size and uniqueness.

\subsubsection{Color}

The color perception process usually causes related feelings or emotions in individuals' brains [39]. This perception or emotion affects consumers' color preferences and can be used to predict their behavioral intention [37]. Consumer perception of a product can be revealed by their selected color choice. Consumer purchases of products are heavily influenced by hints (such as brand names, packages, or colors) from the salespeople. Studies have shown that color affects consumers' aesthetic 
responses to products and attracts consumers to buy the products [37]. Consumers buy what is perceived to be quality, and color conveys meanings of quality to consumers. Smartwatches have a variety of colors and may be matched with multiple colorful straps. For example, the Apple watch introduced a rainbow strap.

\subsubsection{Texture/Touch}

Carbon and Jakesch (2012) proposed the term "haptic aesthetics", which describes the objective qualities (e.g., smoothness, squares) of a product [40]. They thought that haptic aesthetics may have an impact on user-product interaction output measures, such as quality ratings or the fun of using an item. Generally speaking, touch can be considered as a kind of approach behavior. Grohmann, Spangenberg, and Sprott (2007) have pointed out that approach behavior can induce interest, preference, and a more positive attitude [41]. Peck and Wiggins (2006) explored the effectiveness of different types of touch in generating emotional responses [42]. Touch information, or information obtained by hands, has an important impact on the evaluation of products because the material properties of the products are related to quality, hardness, temperature, and weight [41,43]. When consumers are able to conduct a touch evaluation of a product, such behavior will enhance their purchase decisions [37,42]. Swilley's research has shown that texture/touch can play an important role in product evaluation and decision making [37], especially for products in which touch evaluation plays an important role (e.g., clothes and consumer electronics products). Smartwatches are mobile devices with a smaller screen, and texture/touch will become even more important. In addition, smartwatch straps can be changed at will, and different quality straps will give consumers a better experience.

\subsubsection{Shape}

The shape of a product or package affects the purchase intention of consumers and is related to market demand [37]. When in line with social and cultural trends, the shape of a product can become a competitive advantage [36]. Much of the theory of the Gestalt principle of visual perception underlies the explanation of the psychological effects of shape [44]. From a design point of view, different shapes can cause different psychological responses of users. There are a number of design principles related to shape. A circular shape represents empathy, comfort, harmony, warmth, and sensuality, while a square shape represents logic, order, homogeneity, and regularity [19]. The popularity of smartwatches has prompted designers and manufacturers to switch from traditional square screens to circular screens, which is another way to promote market products in the increasingly competitive market for wearable devices. For example, smartwatches such as the Samsung Gear S4 and the Moto 360 have adopted circular screens to distinguish them from earlier square screens. Theoretically speaking, a circular screen can be regarded as an aesthetic or novel cue, which triggers the coldness heuristic. According to Kim's (2017) research, a circular screen is positively related to the hedonic quality of a smartwatch, while a square screen is positively related to a smartwatch's pragmatic quality [19].

\subsubsection{Overall Appearance}

Aesthetics is sometimes used in the beautiful or pleasing appearance of an interactive system [20]. It considers not only a single object but all things related to the whole. The appearance of a product affects consumers' choice of product through a variety of ways, attracts consumers' attention to the product, and brings aesthetic and symbolic value to consumers. Creusen and Schoormans (2005) identified the different ways in which the overall product appearance plays a role in the evaluation and selection of consumer products and provided management recommendations to optimize product appearance [45]. Creusen et al. (2010) further demonstrated that product appearance affects consumer perceptions of function, quality, and ease of use [46]. Electronics companies such as Apple and Samsung have taken the overall aesthetic appearance as a competitive advantage for their products. 


\subsubsection{Screen Size}

The hedonic and pragmatic quality of electronic device screen size plays an important role in providing a more active user experience [38]. The psychological effects of screen size changes have been extensively studied in both fixed (e.g., television) and mobile (e.g., smartphones) environments, and a general conclusion has been reached that screen size is a key factor in achieving a more positive user experience $[19,47]$. A large number of studies have shown that screen size generally has a positive impact on user perceptions in various cognitive and emotional domains, including those related to memory, reality, immersion, presence, and awakening [19,47]. Kim (2017) explored how changes between the screen shape (circular and square) and screen size (large and small) of smartwatches affect their hedonic and pragmatic qualities, as well as the evaluation of transport information. Meanwhile, Kim demonstrated that the screen size of a smartwatch is one of the key factors of its attractiveness [19].

\subsubsection{Uniqueness}

In the domain of consumer behavior research, Tian, Bearden, and Hunter (2001) define consumers' desire for uniqueness as "the trait of pursuing differentness relative to others through the acquisition, utilization, and disposition of consumer goods for developing and enhancing one's self-image and social image" [48]. Consumers are increasingly making product choices based on aesthetic appreciation and uniqueness in visual design. According to the uniqueness theory of Snyder and Fromkin (1977) [49], individuals have varying degrees of unique requirements. If they own a unique product, they will have positive feelings and their pursuit of dissimilarity will be satisfied [38]. In general, before accessing the functional aspects of a product, users will evaluate its novelty and uniqueness and get their first impression from the visual aesthetics of the product before making a purchase decision. Hong and Tam (2006) indicated that uniqueness has a vital impact on behavior intention based on multiple information tools, such as mobile data services [50]. With regards to smartwatches, Choi and Kim (2016) saw the desire for independence as a key determinant of potential smartwatch users' ability to enjoy and express themselves [51]. Dehghani and Kim (2019) proposed that design, uniqueness, and screen size are key components of aesthetic attractiveness and analyzed their role in influencing current smartwatch use behavior and potential user purchase intention [38].

\subsection{Perceived Value and Sustainable Perceived Value}

Value can be said to be a consumer's judgment of his or her own preferences, while perceived value can be defined as the overall evaluation of consumers based on their perceptions of the usefulness of a product. The sustainable perceived value concept in this study was closely related to the green perceived value and ecological perceived value proposed by previous researchers and involved consumers' environmental desires and sustainable consumption $[5,6]$. Sustainable perceived value is not just the value generated by consuming environmentally-friendly products or services but also a way to allow consumers to express their concepts. Such method of promoting sustainable development of ecological resources appears to be provided by the complex pattern of both cognitive and emotional elements. Among these factors, goal-oriented behavior can be dominated by functions, society, and emotional elements [6]. Therefore, testing for sustainable perceived value and how to integrate it into other value constructs, such as functional, emotional, and social values, are effective ways to gain a comprehensive understanding of green consumer behavior.

In the consumer environment of electronics products, consumers rarely act purely rationally; their emotions play a dominant role [6]. Smartwatches, as a hedonic product, will rigger multisensory images, emotional arousal, and fantasies. The consumption of a hedonic product requires emotional involvement and mental effort [17]. Previous scholars have used the theory of consumption values to study the purchase intention of such products [52]. Consumer value theory captures consumer utility in many ways, and these value components are used as a basis for consumers to develop their choice behavior. Sweeney and Soutar (2001) described consumption values as consumer preferences for 
product properties and features [53]. Their consumer perceived value scale conceptualizes perceived value as a combination of functional, social, emotional, and other constructs for pre-or post-purchase product evaluation environments. Many scholars have argued that the motives access to products and services are associated with functional requirements, social values, and emotional values $[14,53]$. Based on these theories, the three first-order constructs of hypothetical functional value, social value, and emotional value in this study were considered a construct of sustainable perceived value.

\subsubsection{Functional Value}

Functionality refers to a range of potential benefits that a product can offer to consumers. Functional value is considered a key factor in consumer choice of product [18]. Functional value in this study referred to the usefulness and ease of use of a product and its ability to facilitate task completion. It represents a goal-oriented, rational, and functional purchase when an individual uses a smartwatch. Moreover, product aesthetics and functional benefits work together to create important first impressions and long-term satisfaction for consumers.

\subsubsection{Social Value}

In making sustainable consumption decisions, consumers can try to contribute to the society in an environmentally friendly manner. Social value, defined as the "perceived utility acquired from an alternative's association with one or more specific social groups" [52], can enhance a person's social self-concept based on the perception of society's assessment of the product [14,53]. Visual aesthetics is carried out for perceived value of wearable devices and serves as a way to improve the quality of life and social life of individuals (that is, social value) [54]. Social value in this study was related to altruism, as buyers may believe that they can improve their social status by choosing attractive consumer electronics products with an environmentally friendly manner.

\subsubsection{Emotional Value}

Emotional value is "the perceived utility acquired from an alternative's capacity to arouse feelings or affective states" [52]. According to attachment theory, consumers tend to develop emotional attachment to products and brands [6]. Emotional sustainability refers to establishing emotional relationships between consumers and products, services, and environments [2]. Recently, as people have come to understand the role of emotion in information technology, Jiang et al. (2016) have held that modern design is over-emphasizing performance issues and under-emphasizing emotional aspects, such as pleasure, interest, and excitement, which are obviously influenced by aesthetics [55]. The aesthetic characteristics of a product can induce an emotional response, attract the attention of consumers, convey product information, and increase awareness of aesthetics [14]. Users' subjective evaluations are influenced by product aesthetics, and their emotional responses to aesthetics can improve their emotional evaluation and overall evaluation of the product [20].

\subsection{Purchase Intention}

Purchase intention is the desire of a consumer to buy a product. Purchase intention can be seen as the consumer's preference for a product or brand when measuring the consumer's purchasing behavior [56]. Wu, Yeh, and Hsiao (2011) considered purchase intention to be an indication of the likelihood that consumers will plan or wish to purchase a product or service [57]. Previous studies have found that the purchase intention for a smartwatch is positively influenced by practicality, functionality and aesthetics [38,58]. In addition, some scholars have put forward the concept of green purchase intention, which refers to the possibility of consumers buying specific products because of their environmental needs [59]. Chen and Chang (2012) suggested that green perceived value has a positive impact on green purchase intention [59]. Environmentally-friendly purchases or green purchases are one aspect of sustainable consumption. 


\section{Model and Hypotheses Development}

In order to measure the aesthetic classification of smartwatches more reasonably, this study established the relationship between interface aesthetics and product form aesthetics, as well as between sustainable perceived value and purchase intention. In this study, interface aesthetics and product form aesthetics were both considered second-order constructs. In addition, sustainable perceived value is a mediating variable of aesthetics and purchase intention and was treated as a second-order construct of functional value, social value and emotional value. The conceptual model is presented in Figure 1.

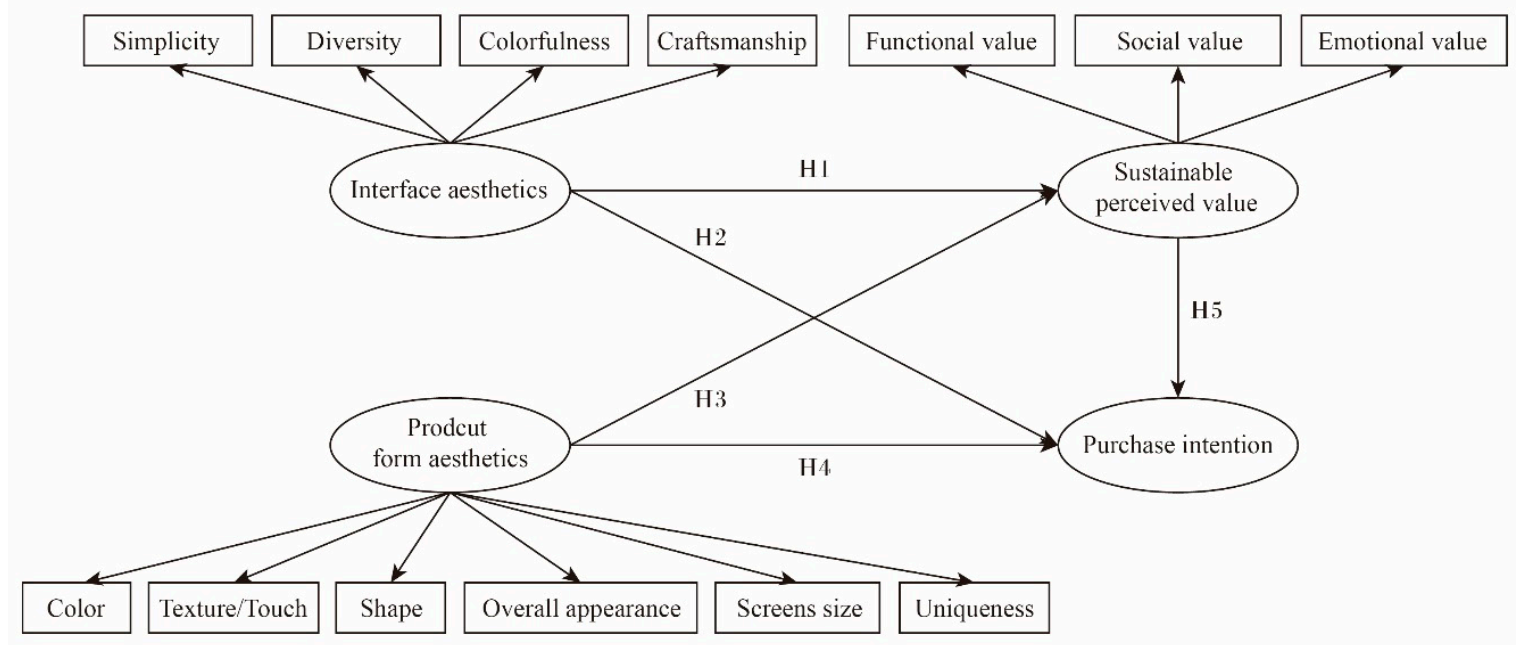

Figure 1. Conceptual research model.

Research on interface aesthetics has shown that interface aesthetics was an important factor in determining the pleasure experienced by users during the interaction process [28]. Yamamoto and Lambert (1994) found that people's aesthetic pleasure has a positive effect on product preferences [60]. Aesthetic pleasure is a positive aesthetic response, which captures response through consumer behavior and is positively related to product preferences [61]. Cyr et al. (2008) argued that the design aesthetics of a mobile interface will affect the perceptions of functions, emotion, and hedonics [62]. The core premise of interface design is that the aesthetic quality of the interface shapes the user experience. In most cases, aesthetics has a positive impact on real performance when users must perform tasks through the user interface. Visually appealing user interfaces lead to more active emotional states (e.g., users feel happier) and greater enjoyment during use. The purchase intention of consumer electronics products is affected by the user interface aesthetics [63]. Hsiao and Chen (2018) proposed that the design aesthetics of smartwatches are positively related to the purchase intention of consumers [16]. Based on the above discussion, this study proposed $\mathrm{H} 1$ and $\mathrm{H} 2$ :

Hypothesis 1 (H1). Interface aesthetics is positively related to sustainable perceived value.

Hypothesis 2 (H2). Interface aesthetics is positively related to purchase intention.

Product appearance serves as a bridge between consumers and a product. This represents the first impression of potential consumers and affects their perceived value [64]. According to the Stimulus-Organism-Response (SOR) model, the aesthetic factor is a visual stimulus that affects behavioral reaction. Such stimulus leads to both cognitive and emotional reactions [14]. According to Cue theory, this stimulus has an impact on consumers' perceived value [65]. A product can be divided into extrinsic and intrinsic cues. Extrinsic cues refer to the brand, packaging, and price of a product, while intrinsic cues refer to the inherent properties of a product, namely its color, shape, quality, and appearance, which represent the aesthetic application of the product. When these inherent 
properties stress an environmentally-friendly manner, they help increase customers' sustainable perceived value for the product.

Product form aesthetics is potentially important for the decision-making processes of consumers. Consumers tend to prefer products with superior designs and develop a preference for products or brands with form aesthetics. Bloch, Brunel, and Arnold (2003) indicated that consumers pay active attention to visual appearance when comparing products, which is a key factor in purchase intention [64]. Lavie and Tractinsky (2004) held that consumers' purchase decisions are strongly influenced by the aesthetic quality of a product [28]. Thus, the following hypotheses are proposed as follows:

Hypothesis 3 (H3). Product form aesthetics is positively related to sustainable perceived value.

Hypothesis 4 (H4). Product form aesthetics is positively related to purchase intention.

Can a beautiful product trigger sustainable perceived value and urge consumers to make a purchase? Many scholars have argued that perceived value is the key factor of purchase intention $[15,16]$. As consumer decisions are often made based on incomplete information, perceived value as a signal has a positive impact on consumer purchase intention [59]. In previous literature, perceived value has been used in different contexts to explore its impact on purchase intention $[16,17,66,67]$. Hsu and Lin (2015) found that emotional value has a strong influence on users' willingness to purchase mobile applications [66]. Jeong et al. (2017) suggested that in a wearable environment, social values have a positive impact on purchase intention [67]. Turel et al. (2010) demonstrated that the overall perceived value of hedonic digital artifacts has a significant impact on future behavioral intent [17]. Hsiao and Chen (2018) found that the attitude of smartwatch use has a positive impact on purchase intention, and that product aesthetics has the most significant impact among these attitude factors [16]. In order to deepen the understanding of smartwatch purchase intention, this study took sustainable perceived value as a mediating variable between aesthetics and purchase intention; therefore, this study proposed $\mathrm{H} 5$ :

Hypothesis 5 (H5). Sustainable perceived value is positively related to purchase intention.

\section{Research Methodology}

\subsection{Measures}

This study modified questionnaire items from previous literature to measure the constructs in the proposed research model of this study. A 7-point Likert scale was used for all items, with scores ranging from "strongly disagree" (1 point) to "strongly agree" (7 points). The items of the first-order constructs for interface aesthetics were adapted from the VisAWI questionnaire by Moshagen and Thielsch (2010) [27]. The items of four first-order constructs (color, texture/touch, shape, and overall appearance) in product form aesthetics were adapted from Toufani, Stanton, and Chikweche (2017) [14], and the items of the other two first-order constructs (screen size and uniqueness) were adapted from Dehghani and Kim (2019) [38]. The items of the first-order constructs for sustainable perceived values were adapted from Koller, Floh, and Zauner (2011) [6], and Chen and Chang (2012) [59]. The measures for purchase intention were adapted from Chen and Chang (2012) and Dehghani and Kim (2019) [38,59].

To ensure the survey questions fit the research background, this study formed two focus groups to discuss the questions. The groups consisted of five product design specialists and ten personnel with smartwatch experience. They modified any questions that were prone to ambiguity or misinterpretation and developed aesthetic structures to reveal potential constructs so that the respondents could fully understand the content and improve the quality of the test [14]. In addition, with the help of the focus groups, this study carried out a pretest. The pretest was used to identify ambiguous representations, clarify proportional resignations, and further refine the questionnaire. After revising 
the first draft, this study conducted a pilot test at a university in Nanjing, China, and collected 68 valid samples. The data from the responses were used to assess the measurement model via factor analysis. As suggested by the accepted standard, this study removed all items with factor loadings below the threshold of 0.5 [68]. Finally, 66 items were retained. The final result of the pilot test showed that the reliability and validity of the test were acceptable.

\subsection{Subject Collection}

The respondents in this study included smartwatch users and potential consumers. Therefore, in order to ensure proper representativeness of research data, this study required that the two types of respondents account for approximately half of the total number. A total of 432 eligible respondents were selected after previous respondent data screening. Additionally, for respondents who have not used smartwatches, this study required that they should take some time to operate smartwatches before participating in the experiment ( 26 smartwatches of various brands are available to facilitate their operation).

The study was conducted in a computer laboratory at a university in Nanjing, China. The laboratory may accommodate 30 people and has 30 computer devices. A total of 432 respondents were randomly assigned to 15 experiments. The respondents were asked to view a website on computer that contained descriptions and videos of a smartwatch before answering the questions. After viewing the website, they began filling out the questionnaire. The respondents took an average of $15 \mathrm{~min}$ to complete the questions. In order to improve the responsiveness and reliability of the respondents, a power bank was awarded to the respondents through a lottery. A total of 425 valid surveys remained after deleting the invalid questionnaires and questionnaires with repeated answers. In addition to eliminating unusable responses, the large sample size of this study results in higher power of statistical analysis and robustness.

In this study, demographic data such as gender, age, education, professional background, and brand preference were investigated, as shown in Table 1. Females accounted for the largest number of respondents $(276,64.94 \%)$, while respondents aged $18-35$ accounted for the largest number $(372,87.53 \%)$. Regarding education level, university accounted for the largest number $(362,85.18 \%)$, and regarding professional background, a background in design accounted for the largest number of respondents $(346,81.41 \%)$. Regarding the use of smartwatches, 52.23 percent of the respondents had used a smartwatch $(222,52.23 \%)$.

Table 1. Demographic Information of Respondents.

\begin{tabular}{cccc}
\hline Measure & Category & Frequency & Percentage (\%) \\
\hline Gender & Male & 149 & 35.06 \\
& Female & 276 & 64.94 \\
\hline \multirow{2}{*}{ Age } & Under 17 & 2 & 47 \\
& $18-35$ & 372 & 87.53 \\
& $36-50$ & 49 & 11.53 \\
& Above 51 & 2 & 47 \\
\hline Educational level & High school and below & 6 & 1.41 \\
& Undergraduate & 362 & 85.18 \\
& Graduate and above & 57 & 13.41 \\
\hline Professional background & Nondesign background & 79 & 18.59 \\
& Design background & 346 & 81.41 \\
\hline \multirow{2}{*}{ Brand } & Unused & 203 & 47.76 \\
& Samsung & 7 & 1.65 \\
& Huawei & 33 & 7.76 \\
& Apple & 99 & 23.29 \\
& Others & 83 & 19.53 \\
\hline
\end{tabular}




\section{Data Analysis}

This study used the partial least squares (PLS) method to analyze the proposed research model and selected SmartPLS (Version 3.2.8) to perform data analysis. Compared with other statistical analysis methods, PLS does not have to evaluate whether the raw data has a multivariate normality allocation and can obtain robust parameter estimation results using a small sample size $[69,70]$. PLS is applicable to discuss causal relationships among construct variables and can be used to measure and construct models simultaneously. In addition, it has a more relaxed requirement for the normality and randomness of variables and is suitable for handling relationships between variables in the distribution of anomalous data. The two phases of PLS analysis and estimation are as follows. Before testing the proposed conceptual model, it is important to ensure that there are no reliability or validity issues with the proposed conceptual model [71]. Therefore, the reliability and validity of the model were analyzed in the first phase, and the path coefficients and interpretation of the model were evaluated and validated in the second phase. The purpose of both phases was to verify the relationship between constructs by checking whether they were reliable and valid [56,72]. This study explored the causal relationships among the interface aesthetics, product form aesthetics, sustainable perceived value, and purchase intention of smartwatches. Previous literature contained numerous measurement items for each construct. Therefore, PLS was more suitable for this study than other structural equation modeling (SEM) methods to study the causal relationships among variables, reduce measurement error, and avoid collinearity. Majchrzak et al. (2005) suggested that the maximum number of recommended model paths should be at least 5 to 10 times the number of samples [73]. In this study, the sample number was 425 and the maximum path number is five, which was in accordance with the minimum sample number standard proposed.

\subsection{Outer Model and Scale Validation}

In PLS, the relationship between the indicator and the latent construct is called the outer model. Relevant tests of the outer model included the reliability of each item and the internal consistency, convergent validity, and discriminant validity of each construct. The corresponding loading of the questions were used to test the reliability of the items. Factor loading presented the extent the construct can be measured by some questions at a threshold of 0.6 , which was used to indicate the individual reliability [74]. After deleting nine items with a low load, all measurement items met the criteria (The Appendix A lists the measurement items). The range of the factor loadings of each item is shown in Table 2. In addition, all composite reliability (CR) values for each construct were higher than the threshold value of 0.7 [69], indicating the constructs were internally consistent. Table 2 shows that the composite reliability values for each construct were higher than 0.7 . In addition, according to Nunnally and Bernstein (1994) [75], corrected item-total correlation (CITC) value should be higher than 0.3 when carrying out reliability analysis through CITC. As Table 2 shows, the CITC value of each construct is higher than the recommended value of 0.3 . Therefore, it can be concluded that the internal consistency of the scales is reliable and that each construct in the measurement model has good reliability. In terms of the convergent validity, in addition to measuring each item using the composite reliability and load factor, the average variance extracted (AVE) indicator for each construct needed to be taken into account to check the convergent validity of each construct. AVE indicators that are greater than 0.5 suggest that the construct has good convergent validity [76]. As can be seen from Table 2, the AVE of the observed variables for each construct in this study ranged from 0.536 to 0.840 , indicating good convergent validity.

Discriminant validity tests the degree of discrimination between tested variables and different constructs criterion. The heterotrait-monotrait ratio (HTMT), proposed by Henseler et al. (2015), could be used on correlations based on the multitrait-multimethod matrix [77]. Therefore, this study adopted HTMT to evaluate the discriminant validity. The discriminant validity was good when the values of HTMT were lower than the threshold of $0.90[56,78]$. As shown in Table 3, the HTMT values between 
all constructs were below the threshold value of 0.90 , indicating satisfactory discriminant validity. In addition, Appendix B lists correlations between the constructs of the model.

Table 2. Reliability and AVE of the outer model.

\begin{tabular}{cccccc}
\hline Construct & Items & $\begin{array}{c}\text { Range of Factor } \\
\text { Loadings }\end{array}$ & $\begin{array}{c}\text { Composite } \\
\text { Reliability }\end{array}$ & AVE & CITC \\
\hline SIM & 3 items & $0.909-0.926$ & 0.940 & 0.840 & $0.795-0.832$ \\
DIV & 3 items & $0.763-0.883$ & 0.871 & 0.693 & $0.524-0.695$ \\
COLF & 3 items & $0.787-0.910$ & 0.903 & 0.757 & $0.565-0.781$ \\
CRA & 3 items & $0.868-0.931$ & 0.931 & 0.817 & $0.724-0.827$ \\
COL & 6 items & $0.706-0.757$ & 0.874 & 0.536 & $0.526-0.651$ \\
T/T & 4 items & $0.811-0.930$ & 0.928 & 0.763 & $0.670-0.859$ \\
SHA & 4 items & $0.814-0.875$ & 0.919 & 0.738 & $0.677-0.772$ \\
OA & 3 items & $0.665-0.811$ & 0.777 & 0.540 & $0.356-0.436$ \\
SS & 2 items & $0.714-0.911$ & 0.800 & 0.670 & $0.362-0.362$ \\
UNI & 3 items & $0.848-0.887$ & 0.904 & 0.758 & $0.693-0.715$ \\
FV & 8 items & $0.663-0.875$ & 0.937 & 0.651 & $0.576-0.822$ \\
SV & 5 items & $0.675-0.864$ & 0.904 & 0.655 & $0.461-0.789$ \\
EV & 6 items & $0.723-0.891$ & 0.941 & 0.729 & $0.632-0.820$ \\
PI & 4 items & $0.849-0.881$ & 0.920 & 0.742 & $0.701-0.786$
\end{tabular}

Note: SIM-simplicity; DIV—diversity; COLF-colorfulness; CRA—craftsmanship; COL-color; T/T—-texture/touch; SHA — shape; OA—overall appearance; SS—screen size; UNI—uniqueness; FV—functional value; SV—social value; EV—emotional value; PI—purchase intention.

Table 3. Results of discriminant validity by HTMT.

\begin{tabular}{|c|c|c|c|c|c|c|c|c|c|c|c|c|c|c|}
\hline & SIM & DIV & COLF & CRA & COL & $\mathrm{T} / \mathrm{T}$ & SHA & OA & SS & UNI & FV & SV & EV & PI \\
\hline SIM & & & & & & & & & & & & & & \\
\hline DIV & 0.759 & & & & & & & & & & & & & \\
\hline COLF & 0.551 & 0.710 & & & & & & & & & & & & \\
\hline CRA & 0.691 & 0.758 & 0.732 & & & & & & & & & & & \\
\hline COL & 0.373 & 0.539 & 0.610 & 0.507 & & & & & & & & & & \\
\hline $\mathrm{T} / \mathrm{T}$ & 0.489 & 0.574 & 0.413 & 0.553 & 0.437 & & & & & & & & & \\
\hline SHA & 0.519 & 0.629 & 0.521 & 0.598 & 0.557 & 0.797 & & & & & & & & \\
\hline $\mathrm{OA}$ & 0.460 & 0.616 & 0.513 & 0.527 & 0.734 & 0.766 & 0.828 & & & & & & & \\
\hline SS & 0.558 & 0.629 & 0.347 & 0.556 & 0.431 & 0.718 & 0.814 & 0.881 & & & & & & \\
\hline UNI & 0.481 & 0.601 & 0.583 & 0.575 & 0.661 & 0.548 & 0.678 & 0.774 & 0.588 & & & & & \\
\hline FV & 0.517 & 0.663 & 0.419 & 0.604 & 0.535 & 0.711 & 0.812 & 0.860 & 0.776 & 0.683 & & & & \\
\hline SV & 0.389 & 0.381 & 0.516 & 0.428 & 0.516 & 0.391 & 0.449 & 0.568 & 0.411 & 0.524 & 0.448 & & & \\
\hline EV & 0.465 & 0.601 & 0.519 & 0.594 & 0.612 & 0.534 & 0.622 & 0.645 & 0.589 & 0.639 & 0.641 & 0.651 & & \\
\hline PI & 0.399 & 0.586 & 0.501 & 0.492 & 0.537 & 0.521 & 0.567 & 0.685 & 0.496 & 0.542 & 0.611 & 0.462 & 0.745 & \\
\hline
\end{tabular}

\subsection{Common Method Bias Testing}

In a questionnaire, there may be common method bias when one respondent completed all the questionnaire items. According to Podsakoff et al. [79], the questionnaire was designed under process control. This study not only revised the questionnaire based on the suggestions of 5 product design experts and 10 experienced smartwatch users, but conducted a pretest to modify semantics of the questionnaire. Harman's one factor test was used to assess whether there was a common-method bias. The basic assumption of Harman's one factor test is that if a single factor or one general factor occupies the majority of the covariance in the measurement, it indicates the existence of common method bias [79]. Harman's one factor test was performed on a complete data set by performing exploratory factor analysis in SPSS. The results of correlation test showed that the variance of the first 
factor did not exceed 50\% of the total explanatory force. The above diagnostic analysis confirms that there is no significant evidence of common method bias in the data analysis of this study.

\subsection{Inner Model and Hypotheses Testing}

In PLS, the path structure between constructs is called the inner model. This study adopted the inner model PLS analysis to test the hypotheses as well as estimate the path coefficients, R-squares, and Q-squares. The path relation represented the intensity and direction of the variable relation, indicating the causal relationship between the observed variable and the latent variable. The R-square value represented the percentage of the dependent variables that could be interpreted and represented the predicted capability of the model. Interface aesthetics, product form aesthetics, and sustainable perceived value were second-order factors. Moreover, bootstrapping was adopted to estimate the significance of each path coefficient in this study. The estimates were more accurate than the commonly-used limit approximations by using duplicate sample data [80]. Therefore, this study used bootstrapping to examine the significant relationships among variables.

The results of the inner model are shown in Figure 2 and Table 4. In the structural model analysis, PLS stressed the variance of each path coefficient and the explained variance $\left(R^{2}\right)$ rather than the simulation of the whole model [70]. The dotted lines in Figure 2 denote the insignificant paths. The $t$-values and path coefficients were placed near the straight line from one construct to another. The constructs of interface aesthetics were shown to have strong effects on sustainable perceived value, thus supporting H1 (IA - SPV: $\beta=0.202, t=4.972, p<0.001$ ). However, interface aesthetics had no significant direct effect on purchase intention; thus, $\mathrm{H} 2$ was not supported (IA $->$ PI: $\beta=0.089, t=1.465$ ). In addition, the constructs of product form aesthetics were shown to have strong effects on sustainable perceived value, thus supporting H3 (PFA - SPV: $\beta=0.674, t=17.675, p<0.001$ ). However, product form aesthetics had no significant direct effect on purchase intention; thus, H4 was not supported (PFA -> PI: $\beta=0.095, t=1.259$ ). Moreover, sustainable perceived value was found to positively and significantly affect purchase intention, thus $\mathrm{H} 5$ was supported (SPV $->$ PI: $\beta=0.544, t=7.717, p<0.001$ ). Finally, the results showed that $67.9 \%$ and $47.1 \%$ of the respective variances of sustainable perceived value and purchase intention could be explained by the research model. In addition, the Q-square values for sustainable perceived value $\left(Q^{2}=0.401\right)$ and purchase intention $\left(Q^{2}=0.530\right)$ were larger than zero, suggesting sufficient predictive power of the proposed model.

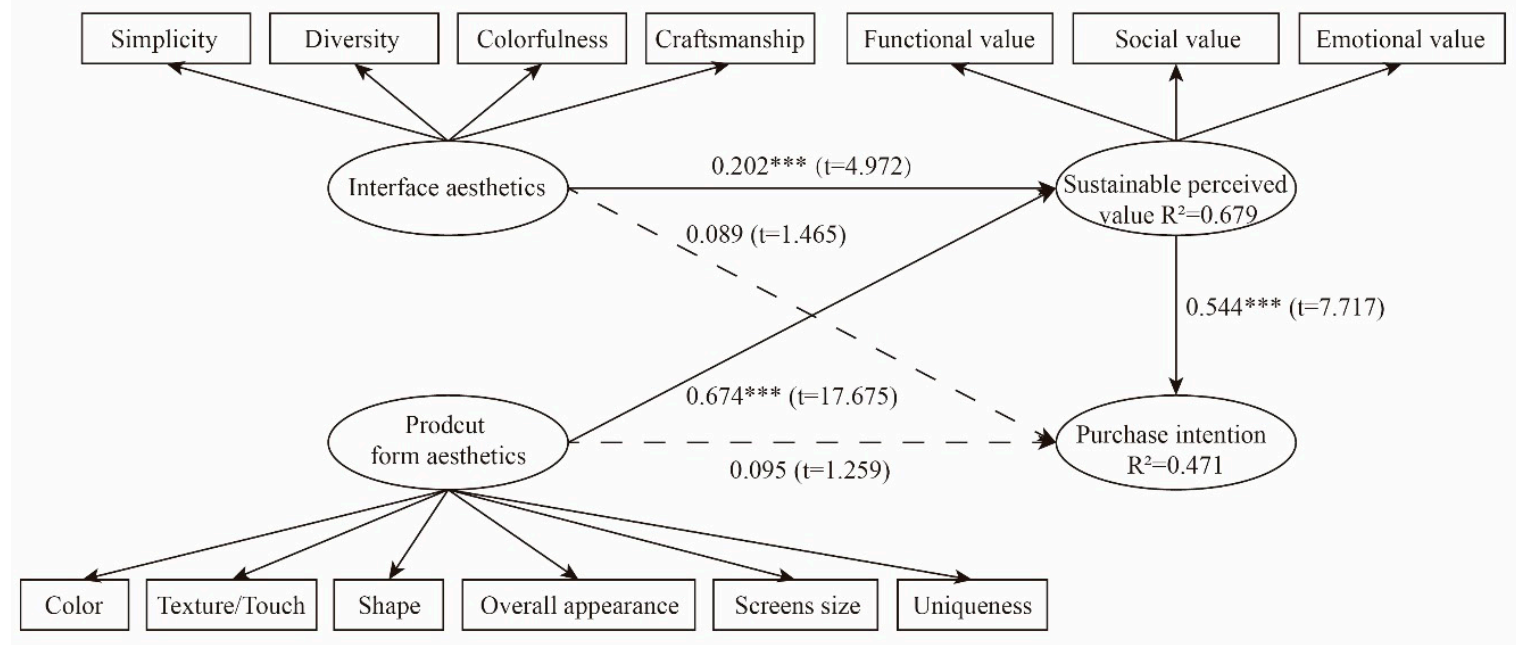

Figure 2. Analysis results. ${ }^{* * *}: p<0.001$.

\subsection{Testing of Mediation Effects}

The results of testing the mediation effects are presented in Table 5. The results showed that sustainable perceived value provided a significant mediation effect between interface aesthetics and 
purchase intention (IA -> SPV $->$ PI: $\beta=0.110, t=4.402, p<0.001$ ). In addition, sustainable perceived value provided a significant mediation effect between product form aesthetics and purchase intention (PFA $->$ SPV $->$ PI: $\beta=0.366, t=6.777, p<0.001$ ).

Table 4. Summary of inner model results.

\begin{tabular}{cccc}
\hline Hypothesis & Path Coefficient & t-Value & Result \\
\hline $\mathrm{H} 1: \mathrm{IA} \rightarrow \mathrm{SPV}$ & $0.202^{* * *}$ & 4.972 & Supported \\
$\mathrm{H} 2: \mathrm{IA} \rightarrow \mathrm{PI}$ & 0.089 & 1.465 & Not Supported \\
$\mathrm{H} 3: \mathrm{PFA} \rightarrow \mathrm{SPV}$ & $0.674^{* * *}$ & 17.675 & Supported \\
$\mathrm{H} 4: \mathrm{PFA} \rightarrow \mathrm{PI}$ & 0.095 & 1.259 & Not Supported \\
$\mathrm{H} 5: \mathrm{SPV} \rightarrow \mathrm{PI}$ & $0.544^{* * *}$ & 7.717 & Supported \\
\hline
\end{tabular}

Note 1: IA-interface aesthetics; PFA—product form aesthetics; SPV—sustainable perceived value; PI—purchase intention; Note 2: ${ }^{*} p$-value $<0.05 ;{ }^{* *} p$-value $<0.01 ; * * * *$-value $<0.001$; Note 3: Number of bootstrap samples $=10,000$.

Table 5. Mediation Effects Testing.

\begin{tabular}{ccccc}
\hline Relationship & Original Sample & Standard Deviation & $\boldsymbol{t}$-Value & $\boldsymbol{p}$-Value \\
\hline $\mathrm{IA} \rightarrow \mathrm{SPV} \rightarrow \mathrm{PI}$ & 0.110 & 0.025 & 4.402 & 0.000 \\
$\mathrm{PFA} \rightarrow \mathrm{SPV} \rightarrow \mathrm{PI}$ & 0.366 & 0.054 & 6.777 & 0.000 \\
\hline
\end{tabular}

Note 1: IA—interface aesthetics; PFA—product form aesthetics; SPV—sustainable perceived value; PI—purchase intention; Note 2: Number of bootstrap samples-10,000.

The present study further used the bootstrapping method with bias-corrected confidence estimates to estimate the effects of the mediators [81]. A 95\% confidence interval of the specific mediating effects was obtained using 10,000 bootstrap resamples. The p-values of the proposed two mediation paths confirmed the existence of significance mediation effects.

\section{Discussion}

\subsection{Classification of Product Aesthetics and Its Impact on Sustainable Perceived Value}

Despite the large amount of literature on product aesthetics, only a small number of studies have examined interface aesthetics or product form aesthetics separately, and they have not included interface aesthetics and product form aesthetics in the study model at the same time. Therefore, based on the structural features of smartwatches, this study measured the constructs of product aesthetics in a more precise and reasonable manner through the new aesthetics classification and stressed the impact of the two categories of aesthetics on sustainable perceived value and purchase intention, which was also a new finding of this study.

Moshagen and Thielsch $(2010,2013)$ suggested that the factors underlying VisAWI are universal enough to be used to measure the visual aesthetics of other human-computer interfaces, while minor revisions could be made to modify the wording of items for websites [27,29]. Based on the results of this study, the modified VisAWI scale was found to be applicable to the visual interface aesthetics measurement of smartwatches. Among them, simplicity and diversity have been regarded as formal parameters of interface aesthetics. Colorfulness is one of the key attributes of interface aesthetics, and craftsmanship involves the skillful and coherent integration of all relevant design dimensions. These four constructs have different weights when measuring interface aesthetics, and they all contribute to the perceptions of smartwatch interface aesthetics. Moreover, they have a positive effect on the sustainable perceived value of smartwatches.

The results showed that all constructs in product form aesthetics had a positive impact on the sustainable perceived value of smartwatches. Product form aesthetics is a key part of consumer perception because it is a way for consumers to naturally perceive and determine the form of a product. Through this simple and effective perceptual processing unity, aesthetic pleasure can be enhanced [82]. Smartwatches are considered a fashionable product, and consumers prefer to choose these wearable 
devices based on aesthetic constructs such as color, texture/touch, shape, overall appearance, and screen size, mainly because smartwatches can be used as a means of visual communication. In the case of uniqueness, the need for uniqueness clearly explains what it means to use a smartwatch [51]. According to Snyder and Fromkin's (1977) uniqueness theory [49], smartwatches are fashionable digital products that are distinct from traditional watches. Their characteristics clearly explain purchase intention toward smartwatches [14], especially individuals' desire for uniqueness, which can further relieve their behavior and emotions and pursue a self-expressive emotional value. Moreover, this emotional value is more likely to be an ecology-oriented sustainable value, emphasizing a lifestyle that promotes the sustainable development of ecological resources.

Product aesthetic perceptions can cause appropriate positive responses, such as simple liking, or they can call for stronger aesthetic responses, similar to aesthetic responses for art products [4]. Aesthetic pleasure is an aesthetic response that is connected with emotion, which can arouse the sensual enjoyment of consumers and guide consumers' spending behavior [83]. According to Chapman (2008) [84], emotionally durable design reduces natural resource consumption and waste by enhancing the durability of the relationship established between consumers and products. Essentially, product replacement is delayed by the strong emotional bond. As a policy approach, emotionally durable design allows consumers to get to know and assign long-term value to a product. Therefore, by exploring the sustainable perceived value of consumers regarding product aesthetics, consumers are encouraged to change towards sustainable values and sustainable lifestyles, as well as incorporate purchase-related and habitual elements that cross conventional behavioral boundaries.

\subsection{Impact of Sustainable Perceived Value on Purchase Intention}

Hsiao and Chen (2018) suggested that social value and performance/quality value will not affect purchase intention [16], because potential consumers may have difficulty accessing the social value of the evaluated product. Performance/quality value is a basic feature of mobile electronic devices. Therefore, such value can hardly become an incentive toward purchase. However, Toufani, Stanton, and Chikweche (2017) argued that purchase intention is most affected by social value and that functional value has no effect on purchase intention [14]. Consumers may want to improve their social image by buying these new consumer electronics products as early adopters because smartwatches are in the early stages of adoption. Smartwatches can be used to signify status and are worn on the body. They become a fashion accessory, thus making it easier than other mobile electronics products to present their innovativeness in daily life. When consumers buy consumer electronics products with an environmentally friendly manner, they present altruistic motives in environmental protection, and those with higher social status tend to have stronger motives [6].

In terms of the functional value of smartwatches, smartwatches work with existing consumer electronics products, such as smartphones or tablet computers, to synchronize data or transport information. Moreover, smartwatches can replace or supplement smartphones with the ability to receive e-mail, send text messages, receive calls, and make payments, thereby making individuals' lives convenient (for example, while driving). In addition, smartwatches can provide wearers with functions such as information about health improvements. Overall, smartwatches meet the functional needs of consumers and have become an important part of the users' daily lives.

Many scholars believe that emotional value has a direct impact on purchase intention towards smartwatches $[14,16]$. Such a view is consistent with the results of this study. Product aesthetics is seen as a key factor in enhancing consumers' emotional association with a particular device because consumer perceptions are important to emotional and cognitive effects. Emotion is significantly aroused by smartwatches through aesthetics, and the sustainable perceived value associated with such emotional association may lead to a more focused and effective sales promotion strategy and promote the purchase intention of consumers. In addition, Chapman (2015) suggested that sustainability issues can be resolved by exploring the lifecycle of a product and connecting it to people's emotional needs [85]. 
Therefore, the results showed that sustainable perceived value (functional value, social value, and emotional value) has a positive effect on the purchase intention for smartwatches.

\subsection{Sustainable Perceived Value is a Key Factor for Aesthetics to Driving Purchase Intention}

The results of this study showed that, surprisingly, neither interface aesthetics nor product form aesthetics has a direct impact on purchase integration, and are mediated by sustainable perceived value to have a positive impact on purchase intention. Hsiao and Chen (2018) suggested that design aesthetics enhances consumer purchase intention by using their attitude toward smartwatch [16]. Toufani, Stanton, and Chikweche (2017) found that aesthetics has a significant but relatively weak direct relationship with purchase intention (compared with its indirect effects) [14]. Consumers preparing to buy consumer electronics products, such as smartwatches, may first be attracted to the appearance of the product, but more importantly they will consider the value they get from the product, which will be an important determinant of purchase intention. Therefore, this study considered sustainable perceived value as a mediating variable that plays a key role in enhancing purchase intention.

The consumer electronics products industry currently plays a non-sustainable role in the environment, and many consumer electronics products companies are in a non-sustainable state of development. Sustainable product design is a vital part of current sustainable development and can be used to extend product lifespan using a design approach based on lifecycle considerations. In addition to physically extending the lifetime of a product, design concepts based on emotional durability is an effective method. In his book titled "Emotionally Durable Design: Objects, Experiences \& Empathy", Chapman (2015) described the complexity of emotional-driven consumption processes, which goes far beyond inadvertent purchases of trendy and cool things [85]. To promote sustainability, designers need to focus on enhancing long-term product-empathic relationships. Niinimäki and Koskinen (2011) promoted sustainable product relationships by deepening their understanding of consumer needs, values, and emotions with an empathic approach [86].

\subsection{Managerial Implications}

The model used in this study validated the positive impact of interface aesthetics and product form aesthetics on different constructs of sustainable perceived value and sustainable perceived value on purchase intention. The four constructs (simplicity, diversity, colorfulness, and craftsmanship) in interface aesthetics reflect consumer evaluations of the visual appearance of the interface of a smartwatch. Color, texture/touch, shape, overall appearance, screen size, and uniqueness form aesthetics constructs all contribute to the aesthetic appreciation of a smartwatch. The conceptual model presented in this study showed that through the syntheses of interface aesthetics and product form aesthetics, the impact of the two categories of aesthetics on purchase intention could be analyzed more accurately, and some design recommendations could be provided for product designers. In the future, designers need to provide satisfying and consistent use experiences when designing products, such as products that incorporate environmental protection concepts and satisfying aesthetic experiences. At the same time, it is necessary to create challenges for marketers to understand the most appealing synthesis of these attributes, emphasize the need for such syntheses in new smartwatch development, and promote such syntheses in integrated marketing broadcasts. Linking the aesthetic value of smartwatches directly or indirectly with purchase intention could help to better understand the business value of product aesthetics, more accurately identify customer demand for smartwatches, and consider how aesthetics can be used to promote smartwatch research, positioning, and sales.

From a management perspective, the study of smartwatch aesthetic constructs could help companies reduce the likelihood of failure in innovation, provide opportunities for companies to improve the properties of new products, meet differentiated or segmented market demands, and obtain more accurate market positioning and sales strategies in the market. More importantly, in order to mitigate the adverse impact of obsolete consumer electronics products on the environment, companies need to push "closed-loop environmentally sustainable production" of consumer electronics products. 
Corporate environmentalism recognizes and integrates environmental concerns into the company's decision-making process to achieve sustainable management. Such trend has become popular in many companies. In addition, at the product management level, attention to sustainable perceived value can be an important factor in future managing decisions. This study identified factors related to sustainability and established relationships among product aesthetics, sustainable perceived value, and purchase intentions. This could provide useful information for smartwatch industry managers to design more effective and environmentally-friendly product development and marketing strategies. The sustainable perceived value mentioned in this study may be more important than designing and manufacturing products. Instead of merely focusing on product design aesthetics or improving ecological efficiency of product manufacturing process, consumers need to develop deeper emotional relationships with products, so as to form a deeper attachment and care for the product. Therefore, sustainable development should place more attention to consumer behavior, so as to lead consumers to move towards sustainable eco-development and promote the sustainable development of the consumer electronics product industry.

\section{Conclusions}

This study took smartwatches as the research subjects and proposed a conceptual model to test the effects of interface aesthetics and product form aesthetics on sustainable perceived value and purchase intention. The results showed that sustainable perceived value plays a key role in boosting purchase intention through product aesthetics. It arouses customer purchase intention through the direct contact between product aesthetics and sustainable perceived value. In addition, this study expanded the aesthetic perception of smartwatches to consumer electronics products by analyzing the relationship among interface aesthetics, product form aesthetics, sustainable perceived value, and purchase intention, so as to develop aesthetic constructs for information technology equipment. Increasing the emotional durability established between consumers and products through sustainable perceived value to prolong the life of products reduces resource consumption and waste costs, and promotes the sustainable development of ecological resources. The contributions of this study were as follows:

- With the development of technology, consumer electronic products are increasingly equipped with more touch-screen interfaces. In this study, a new product aesthetics classification was established, which divides product aesthetics into interface aesthetics and product form aesthetics, and a conceptual model was proposed to measure the constructs of product aesthetics more accurately and reasonably so as to provide a research basis for the measurement methods of product aesthetics.

- In addition, this study also examined the visual aesthetics measurements of VisAWI in other human-computer interfaces, thereby further enhancing the theory and existence value of Moshagen and Thielsch's $(2010,2013)$ perception of visual aesthetics [27,29].

- The results showed that interface aesthetics and product form aesthetics have positive effects on sustainable perceived value but have no direct effects on the purchase intention of consumers. Moreover, interface aesthetics and product form aesthetics must be mediated by sustainable perceived value in order to have a positive impact on consumer purchase intention. Therefore, sustainable perceived value is a mediator between product aesthetics (interface aesthetics and product form aesthetics) and purchase intention. Moreover, sustainable perceived value helps designers better understand consumer demand, value, and long-term product relationships.

- This study proposed the novel concept of sustainable perceived value, which can test the sustainable perceived value, and explore the integration into other value constructs (functional, social, and emotional values). It is an effective way to gain a more comprehensive understanding of how to promote the sustainable development of ecological resources. It could be said that sustainable perceived value greatly affects consumers' green consumer behavior. 


\section{Limitations and Future Research}

For the consumer electronics industry, efforts should be made to further implement more effective and environmentally-friendly product development and sales strategies, and provide design advice to product designers. In addition, how to understand more effectively the value and demand of consumers at a deeper level, and how to lay the foundation for more sustainable design through practical design methods, will be a future research direction. Second, smartwatch interfaces differ from websites in that they actually belong to the mobile interface. People often view smartwatches when they are in a moving state. The respondents in this study included smartwatch users and potential consumers. Therefore, this study collected research data through a questionnaire. Future researches may conduct experimental research on the mobile interface aesthetics of smartwatches. Thirdly, in order to ensure the strong relationship between aesthetics and purchase intention and the mediating effect of sustainable perceived value, this study excluded other factors, such as brand influence, bundled services, and price. The respondents may have had different visual preferences for the products, therefore the effects of this potential heterogeneity were also excluded [14]. Fourth, multiple group analysis can be used in the future to test whether predefined data sets differ significantly in their group-specific parameter estimates (e.g., outer weights, outer loadings, and path coefficients). Finally, the respondents come from China, and results could vary from country to country due to differences in culture and lifestyle. In addition, individual differences among respondents were not examined in this study. Future studies could improve the universality of the results by adding factors such as gender, age, and region. Despite the limitations of this study, a new product aesthetics classification was established. In addition, it was found that sustainable perceived value is a key factor in harmonizing aesthetics and purchase intention, which could be helpful in understanding the sustainable perceived value of product aesthetics in consumer the electronics products industry and could lay a foundation for future research.

Author Contributions: Conceptualization, J.W. and Y.H.; data curation, J.W.; formal analysis, J.W.; Investigation, J.W.; methodology, J.W.; J.W. wrote the manuscript with the supervision from Y.H.; and Y.H. acted as a corresponding author.

Funding: This research received no external funding.

Conflicts of Interest: The authors declare no conflict of interest.

\section{Appendix A}

Table A1. Questionnaire Items.

\begin{tabular}{|c|c|c|c|}
\hline Constructs & Item Number & Items & Source \\
\hline \multirow[b]{2}{*}{ Simplicity } & SIM 1 & The layout of the smartwatch's interface is easy to grasp. & \multirow{2}{*}{$\begin{array}{l}\text { Moshagen and } \\
\text { Thielsch (2010) }\end{array}$} \\
\hline & SIM 2 & Everything goes together on this smartwatch's interface. & \\
\hline \multirow[b]{2}{*}{ Diversity } & DIV 1 & The layout of the smartwatch's interface is pleasantly varied. & \multirow{2}{*}{$\begin{array}{l}\text { Moshagen and } \\
\text { Thielsch (2010) }\end{array}$} \\
\hline & DIV 2 & The layout of the smartwatch's interface is inventive. & \\
\hline \multirow{3}{*}{ Colorfulness } & COLF 1 & The color composition of the smartwatch's interface is attractive. & \multirow{3}{*}{$\begin{array}{l}\text { Moshagen and } \\
\text { Thielsch (2010) }\end{array}$} \\
\hline & COLF 2 & The colors of the smartwatch's interface are appealing. & \\
\hline & COLF 3 & The color selection of the smartwatch's interface is various. & \\
\hline \multirow[b]{2}{*}{ Craftsmanship } & CRA 1 & The layout of the smartwatch's interface appears professionally designed. & \multirow{2}{*}{$\begin{array}{l}\text { Moshagen and } \\
\text { Thielsch (2010) }\end{array}$} \\
\hline & CRA 2 & The smartwatch's interface is designed with care. & \\
\hline \multirow{4}{*}{ Color } & COL 3 & I should be able to choose a smartwatch that is multi-colored. & \multirow{4}{*}{$\begin{array}{c}\text { Toufani, Stanton, } \\
\text { and Chikweche } \\
\text { (2017) }\end{array}$} \\
\hline & COL 4 & A smartwatch should have contrasting colors that accent its presence. & \\
\hline & COL 5 & A smartwatch should come in bright colors such as red, orange, and yellow. & \\
\hline & COL 6 & The color of my smartwatch should be attention getting. & \\
\hline
\end{tabular}


Table A1. Cont.

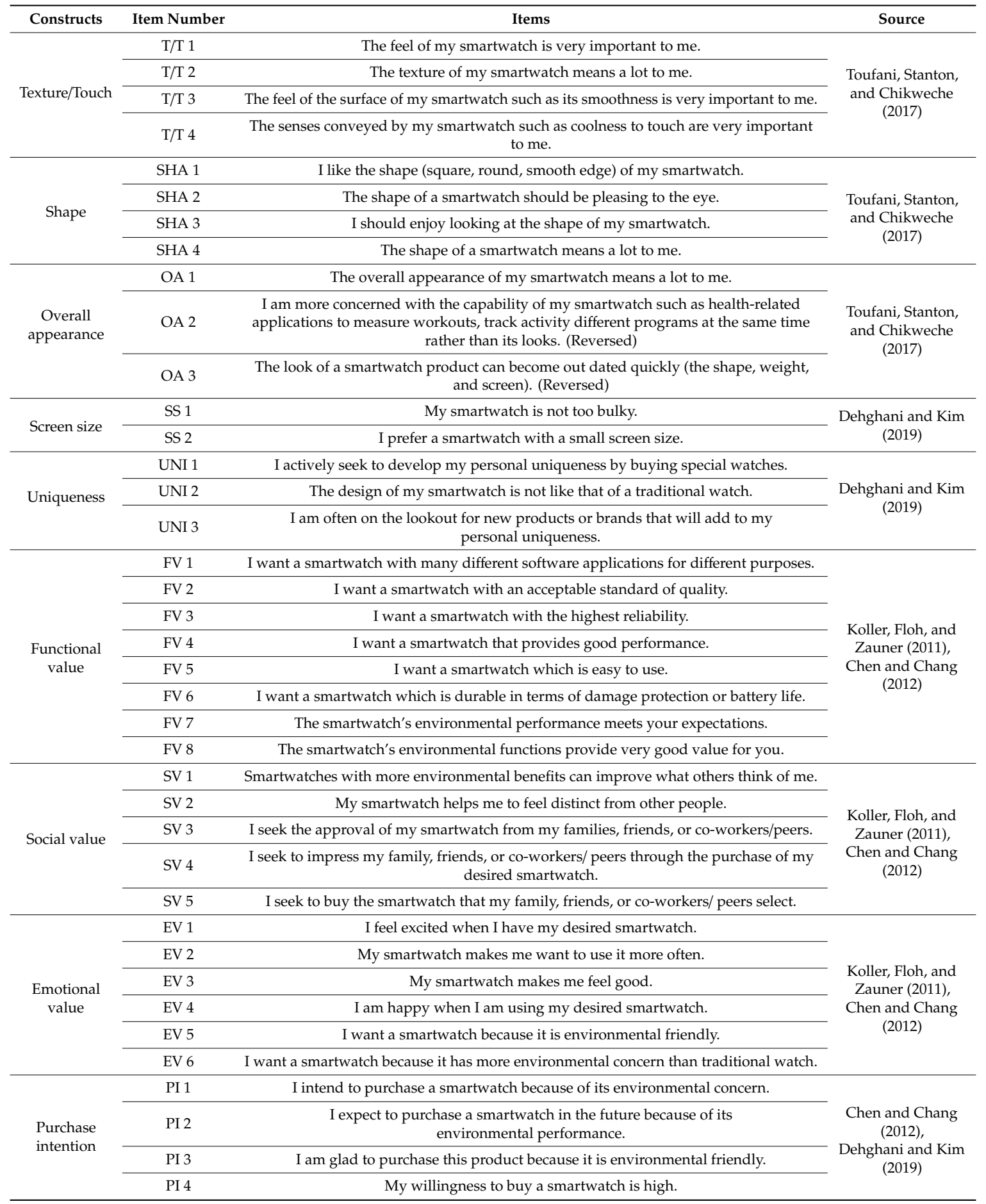




\section{Appendix B}

Table A2. Correlation Matrix between the constructs of the model.

\begin{tabular}{|c|c|c|c|c|c|c|c|c|c|c|c|c|c|c|}
\hline & SIM & DIV & COLF & CRA & COL & $\mathrm{T} / \mathrm{T}$ & SHA & OA & SS & UNI & FV & SV & EV & PI \\
\hline SIM & 1 & & & & & & & & & & & & & \\
\hline DIV & 0.639 & 1 & & & & & & & & & & & & \\
\hline COLF & 0.480 & 0.571 & 1 & & & & & & & & & & & \\
\hline CRA & 0.621 & 0.632 & 0.632 & 1 & & & & & & & & & & \\
\hline COL & 0.331 & 0.442 & 0.506 & 0.442 & 1 & & & & & & & & & \\
\hline $\mathrm{T} / \mathrm{T}$ & 0.441 & 0.477 & 0.356 & 0.496 & 0.386 & 1 & & & & & & & & \\
\hline SHA & 0.463 & 0.517 & 0.445 & 0.531 & 0.487 & 0.710 & 1 & & & & & & & \\
\hline $\mathrm{OA}$ & 0.351 & 0.435 & 0.368 & 0.406 & 0.521 & 0.602 & 0.642 & 1 & & & & & & \\
\hline SS & 0.400 & 0.427 & 0.230 & 0.401 & 0.297 & 0.547 & 0.592 & 0.521 & 1 & & & & & \\
\hline UNI & 0.424 & 0.486 & 0.488 & 0.499 & 0.556 & 0.482 & 0.589 & 0.561 & 0.414 & 1 & & & & \\
\hline FV & 0.473 & 0.559 & 0.366 & 0.550 & 0.482 & 0.648 & 0.734 & 0.655 & 0.578 & 0.608 & 1 & & & \\
\hline SV & 0.352 & 0.320 & 0.444 & 0.382 & 0.448 & 0.352 & 0.405 & 0.418 & 0.267 & 0.461 & 0.413 & 1 & & \\
\hline EV & 0.427 & 0.512 & 0.454 & 0.541 & 0.536 & 0.488 & 0.562 & 0.500 & 0.408 & 0.561 & 0.598 & 0.587 & 1 & \\
\hline PI & 0.358 & 0.490 & 0.431 & 0.440 & 0.460 & 0.469 & 0.506 & 0.512 & 0.359 & 0.471 & 0.559 & 0.412 & 0.675 & 1 \\
\hline
\end{tabular}

Note: SIM-simplicity; DIV—diversity; COLF-colorfulness; CRA—craftsmanship; COL-color; T/T—texture/touch; SHA — shape; OA—overall appearance; SS—screen size; UNI—uniqueness; FV—functional value; SV—-social value; EV—emotional value; PI—purchase intention.

\section{References}

1. Jordan, P.W. Human factors for pleasure in product use. Appl. Ergon. 1998, 29, 25-33. [CrossRef]

2. McDonagh-Philp, D.; Lebbon, C. The emotional domain in product design. Des. J. 2000, 3, 31-43. [CrossRef]

3. Kumar, D.S.; Purani, K.; Sahadev, S. Visual service scape aesthetics and consumer response: A holistic model. J. Serv. Mark. 2017, 31, 556-573. [CrossRef]

4. Bloch, P.H. Seeking the ideal form: Product design and consumer response. J. Mark. 1995, 59, 16-29. [CrossRef]

5. Chen, Y.S. Towards green loyalty: Driving from green perceived value, green satisfaction, and green trust. Sustain. Dev. 2013, 21, 294-308. [CrossRef]

6. Koller, M.; Floh, A.; Zauner, A. Further insights into perceived value and consumer loyalty: A "green" perspective. Psychol. Mark. 2011, 28, 1154-1176. [CrossRef]

7. Paul, J.; Modi, A.; Patel, J. Predicting green product consumption using theory of planned behavior and reasoned action. J. Retail. Consum. Serv. 2016, 29, 123-134. [CrossRef]

8. Hoover, J.; Johnson, K.; Boghrati, R.; Graham, J.; Dehghani, M. Moral framing and charitable donation: Integrating exploratory social media analyses and confirmatory experimentation. Collabra Psychol. $2018,4,9$. [CrossRef]

9. Balconi, M.; Sebastiani, R.; Angioletti, L. A Neuroscientific Approach to Explore Consumers' Intentions Towards Sustainability within the Luxury Fashion Industry. Sustainability 2019, 11, 5105. [CrossRef]

10. Lobos, A.; Babbitt, C. Integrating emotional attachment and sustainability in electronic product design. Challenges 2013, 4, 19-33. [CrossRef]

11. Desmet, P.M.; Hekkert, P. Special issue editorial: Design \& emotion. Int. J. Des. 2009, 3, 1-6.

12. Hassenzahl, M.; Tractinsky, N. User experience-A research agenda. Behav. Inf. Technol. 2006, $25,91-97$. [CrossRef]

13. Jung, Y.; Kim, S.; Choi, B. Consumer valuation of the wearables: The case of smartwatches. Comput. Hum. Behav. 2016, 63, 899-905. [CrossRef]

14. Toufani, S.; Stanton, J.P.; Chikweche, T. The importance of aesthetics on customers' intentions to purchase smartphones. Mark. Intell. Plan. 2017, 35, 316-338. [CrossRef]

15. Hong, J.-C.; Lin, P.-H.; Hsieh, P.-C. The effect of consumer innovativeness on perceived value and continuance intention to use smartwatch. Comput. Hum. Behav. 2017, 67, 264-272. [CrossRef]

16. Hsiao, K.-L.; Chen, C.-C. What drives smartwatch purchase intention? Perspectives from hardware, software, design, and value. Telemat. Inform. 2018, 35, 103-113. [CrossRef] 
17. Turel, O.; Serenko, A.; Bontis, N. User acceptance of hedonic digital artifacts: A theory of consumption values perspective. Inf. Manag. 2010, 47, 53-59. [CrossRef]

18. Yang, H.; Yu, J.; Zo, H.; Choi, M. User acceptance of wearable devices: An extended perspective of perceived value. Telemat. Inform. 2016, 33, 256-269. [CrossRef]

19. Kim, K.J. Shape and size matter for smartwatches: Effects of screen shape, screen size, and presentation mode in wearable communication. J. Comput. Mediat. Commun. 2017, 22, 124-140. [CrossRef]

20. Tuch, A.N.; Roth, S.P.; HornbæK, K.; Opwis, K.; Bargas-Avila, J.A. Is beautiful really usable? Toward understanding the relation between usability, aesthetics, and affect in HCI. Comput. Hum. Behav. 2012, 28, 1596-1607. [CrossRef]

21. Bloch, P.H. Product design and marketing: Reflections after fifteen years. J. Prod. Innov. Manag. 2011, 28, 378-380. [CrossRef]

22. Kurosu, M.; Kashimura, K. Apparent usability vs. inherent usability: Experimental analysis on the determinants of the apparent usability. In Proceedings of the Conference Companion on Human Factors in Computing Systems, Denver, CO, USA, 7-11 May 1995; ACM: New York, NY, USA, 1995; pp. 292-293.

23. Hallnäs, L.; Redström, J. From use to presence: On the expressions and aesthetics of everyday computational things. ACM Trans. Comput. Hum. Interact. (TOCHI) 2002, 9, 106-124. [CrossRef]

24. Kim, J.; Lee, J.; Choi, D. Designing emotionally evocative homepages: An empirical study of the quantitative relations between design factors and emotional dimensions. Int. J. Hum. Comput. Stud. 2003, 59, 899-940. [CrossRef]

25. Miniukovich, A.; De Angeli, A. Visual impressions of mobile app interfaces. In Proceedings of the 8th Nordic Conference on Human-Computer Interaction: Fun, Fast, Foundational, Helsinki, Finland, 26-30 October 2014; ACM: New York, NY, USA, 2014; pp. 31-40.

26. Choi, J.H.; Lee, H.-J. Facets of simplicity for the smartphone interface: A structural model. Int. J. Hum. Comput. Stud. 2012, 70, 129-142. [CrossRef]

27. Moshagen, M.; Thielsch, M.T. Facets of visual aesthetics. Int. J. Hum. Comput. Stud. 2010, 68, 689-709. [CrossRef]

28. Lavie, T.; Tractinsky, N. Assessing dimensions of perceived visual aesthetics of web sites. Int. J. Hum. Comput. Stud. 2004, 60, 269-298. [CrossRef]

29. Moshagen, M.; Thielsch, M. A short version of the visual aesthetics of websites inventory. Behav. Inf. Technol. 2013, 32, 1305-1311. [CrossRef]

30. Seckler, M.; Opwis, K.; Tuch, A.N. Linking objective design factors with subjective aesthetics: An experimental study on how structure and color of websites affect the facets of users' visual aesthetic perception. Comput. Hum. Behav. 2015, 49, 375-389. [CrossRef]

31. Berlyne, D.E. Aesthetics and Psychobiology; Appleton-Century-Crofts: New York, NY, USA, 1971; Volume 336.

32. Karvonen, K. The beauty of simplicity. In Proceedings of the 2000 Conference on Universal Usability, Arlington, VA, USA, 16-17 November 2000; ACM: New York, NY, USA, 2000; pp. 85-90.

33. Reber, R. Processing fluency, aesthetic pleasure, and culturally shared taste. Aesthetic Sci. Connect. Mind Brain Exp. 2012, 223-249. [CrossRef]

34. Lin, S.-W.; Lo, L.Y.-S.; Huang, T.K. Visual Complexity and Figure-Background Color Contrast of E-Commerce Websites: Effects on Consumers' Emotional Responses. In Proceedings of the 201649 th Hawaii International Conference on System Sciences (HICSS), Koloa, HI, USA, 5-8 January 2016; IEEE: Piscataway, NJ, USA, 2016; pp. 3594-3603.

35. Cyr, D.; Head, M.; Larios, H. Colour appeal in website design within and across cultures: A multi-method evaluation. Int. J. Hum. Comput. Stud. 2010, 68, 1-21. [CrossRef]

36. Mugge, R.; Dahl, D.W.; Schoormans, J.P. “What You See, Is What You Get?” Guidelines for Influencing Consumers' Perceptions of Consumer Durables through Product Appearance. J. Prod. Innov. Manag. 2018, 35, 309-329. [CrossRef]

37. Swilley, E. Aesthetic technology: Scale development and measurement. Int. J. Technol. Mark. 2012, 7, 324-341. [CrossRef]

38. Dehghani, M.; Kim, K.J. The effects of design, size, and uniqueness of smartwatches: Perspectives from current versus potential users. Behav. Inf. Technol. 2019, 1-11. [CrossRef]

39. Jiang, Q.; Chen, L.-C.; Zhang, J. Perception and Preference Analysis of Fashion Colors: Solid Color Shirts. Sustainability 2019, 11, 2405. [CrossRef] 
40. Carbon, C.-C.; Jakesch, M. A model for haptic aesthetic processing and its implications for design. Proc. IEEE 2012, 101, 2123-2133. [CrossRef]

41. Grohmann, B.; Spangenberg, E.R.; Sprott, D.E. The influence of tactile input on the evaluation of retail product offerings. J. Retail. 2007, 83, 237-245. [CrossRef]

42. Peck, J.; Wiggins, J. It just feels good: Customers' affective response to touch and its influence on persuasion. J. Mark. 2006, 70, 56-69.

43. Peck, J.; Childers, T.L. To have and to hold: The influence of haptic information on product judgments. J. Mark. 2003, 67, 35-48. [CrossRef]

44. Rock, I.; Palmer, S. The legacy of Gestalt psychology. Sci. Am. 1990, 263, 84-91. [CrossRef]

45. Creusen, M.E.; Schoormans, J.P. The different roles of product appearance in consumer choice. J. Prod. Innov. Manag. 2005, 22, 63-81. [CrossRef]

46. Creusen, M.E.; Veryzer, R.W.; Schoormans, J.P. Product value importance and consumer preference for visual complexity and symmetry. Eur. J. Mark. 2010, 44, 1437-1452. [CrossRef]

47. Kim, K.J.; Sundar, S.S. Does screen size matter for smartphones? Utilitarian and hedonic effects of screen size on smartphone adoption. Cyberpsychol. Behav. Soc. Netw. 2014, 17, 466-473. [CrossRef] [PubMed]

48. Tian, K.T.; Bearden, W.O.; Hunter, G.L. Consumers' need for uniqueness: Scale development and validation. J. Consum. Res. 2001, 28, 50-66. [CrossRef]

49. Snyder, C.R.; Fromkin, H.L. Abnormality as a positive characteristic: The development and validation of a scale measuring need for uniqueness. J. Abnorm. Psychol. 1977, 86, 518. [CrossRef]

50. Hong, S.-J.; Tam, K.Y. Understanding the adoption of multipurpose information appliances: The case of mobile data services. Inf. Syst. Res. 2006, 17, 162-179. [CrossRef]

51. Choi, J.; Kim, S. Is the smartwatch an IT product or a fashion product? A study on factors affecting the intention to use smartwatches. Comput. Hum. Behav. 2016, 63, 777-786. [CrossRef]

52. Sheth, J.N.; Newman, B.I.; Gross, B.L. Why we buy what we buy: A theory of consumption values. J. Bus. Res. 1991, 22, 159-170. [CrossRef]

53. Sweeney, J.C.; Soutar, G.N. Consumer perceived value: The development of a multiple item scale. J. Retail. 2001, 77, 203-220. [CrossRef]

54. Lin, K.-Y.; Chien, C.-F.; Kerh, R. UNISON framework of data-driven innovation for extracting user experience of product design of wearable devices. Comput. Ind. Eng. 2016, 99, 487-502. [CrossRef]

55. Jiang, Z.; Wang, W.; Tan, B.C.; Yu, J. The determinants and impacts of aesthetics in users' first interaction with websites. J. Manag. Inf. Syst. 2016, 33, 229-259. [CrossRef]

56. Chen, S.-C.; Lin, C.-P. Understanding the effect of social media marketing activities: The mediation of social identification, perceived value, and satisfaction. Technol. Forecast. Soc. Chang. 2019, 140, 22-32. [CrossRef]

57. Wu, P.C.; Yeh, G.Y.-Y.; Hsiao, C.-R. The effect of store image and service quality on brand image and purchase intention for private label brands. Australas. Mark. J. (AMJ) 2011, 19, 30-39. [CrossRef]

58. Chuah, S.H.-W.; Rauschnabel, P.A.; Krey, N.; Nguyen, B.; Ramayah, T.; Lade, S. Wearable technologies: The role of usefulness and visibility in smartwatch adoption. Comput. Hum. Behav. 2016, 65, 276-284. [CrossRef]

59. Chen, Y.-S.; Chang, C.-H. Enhance green purchase intentions: The roles of green perceived value, green perceived risk, and green trust. Manag. Decis. 2012, 50, 502-520. [CrossRef]

60. Yamamoto, M.; Lambert, D.R. The impact of product aesthetics on the evaluation of industrial products. J. Prod. Innov. Manag. 1994, 11, 309-324. [CrossRef]

61. Graf, L.K.; Landwehr, J.R. Aesthetic pleasure versus aesthetic interest: The two routes to aesthetic liking. Front. Psychol. 2017, 8, 15. [CrossRef]

62. Cyr, D.; Head, M. Hedonic and utilitarian outcomes of website social presence: The impacts of framing and time constraints. SIGHCI 2008 Proc. 2008, 17, 35-39.

63. Schmidt, T.; Wolff, C. The Influence of User Interface Attributes on Aesthetics. i-com 2018, 17, 41-55. [CrossRef]

64. Bloch, P.H.; Brunel, F.F.; Arnold, T.J. Individual differences in the centrality of visual product aesthetics: Concept and measurement. J. Consum. Res. 2003, 29, 551-565. [CrossRef]

65. Richardson, P.S.; Dick, A.S.; Jain, A.K. Extrinsic and intrinsic cue effects on perceptions of store brand quality. J. Mark. 1994, 58, 28-36. [CrossRef] 
66. Hsu, C.-L.; Lin, J.C.-C. What drives purchase intention for paid mobile apps?-An expectation confirmation model with perceived value. Electron. Commer. Res. Appl. 2015, 14, 46-57. [CrossRef]

67. Jeong, S.C.; Kim, S.-H.; Park, J.Y.; Choi, B. Domain-specific innovativeness and new product adoption: A case of wearable devices. Telemat. Inform. 2017, 34, 399-412. [CrossRef]

68. Hair, J.F.; Black, W.C.; Babin, B.J.; Anderson, R.E.; Tatham, R.L. Análise Multivariada de Dados; Bookman Editora: Porto Alegre, Brazil, 2009.

69. Chin, W.W. The partial least squares approach to structural equation modeling. Mod. Methods Bus. Res. 1998, 295, 295-336.

70. Chin, W.W.; Newsted, P.R. Structural equation modeling analysis with small samples using partial least squares. Stat. Strateg. Small Sample Res. 1999, 1, 307-341.

71. Centobelli, P.; Cerchione, R.; Singh, R. The impact of leanness and innovativeness on environmental and financial performance: Insights from Indian SMEs. Int. J. Prod. Econ. 2019, 212, 111-124.

72. Anderson, J.C.; Gerbing, D.W. Structural equation modeling in practice: A review and recommended two-step approach. Psychol. Bull. 1988, 103, 411-423. [CrossRef]

73. Majchrzak, A.; Malhotra, A.; John, R. Perceived individual collaboration know-how development through information technology-enabled contextualization: Evidence from distributed teams. Inf. Syst. Res. 2005, 16, 9-27. [CrossRef]

74. Hair, J.; Black, W.C.; Babin., B.J.; Anderson, R.E. Multivariate Data Analysis, a Global Perspective, 7th ed.; Pearson: Upper Saddle River, NJ, USA, 2010; p. 816.

75. Nunnally, J.C.; Bernstein, I.H. Psychometric Theory, 3rd ed.; McGraw-Hill: New York, NY, USA, 1994.

76. Fornell, C.; Larcker, D.F. Evaluating structural equation models with unobservable variables and measurement error. J. Mark. Res. 1981, 18, 39-50. [CrossRef]

77. Henseler, J.; Ringle, C.M.; Sarstedt, M. A new criterion for assessing discriminant validity in variance-based structural equation modeling. J. Acad. Mark. Sci. 2015, 43, 115-135. [CrossRef]

78. Gold, A.H.; Malhotra, A.; Segars, A.H. Knowledge management: An organizational capabilities perspective. J. Manag. Inf. Syst. 2001, 18, 185-214. [CrossRef]

79. Podsakoff, P.M.; MacKenzie, S.B.; Lee, J.-Y.; Podsakoff, N.P. Common method biases in behavioral research: A critical review of the literature and recommended remedies. J. Appl. Psychol. 2003, 88, 879-903. [CrossRef] [PubMed]

80. Purvis, R.L.; Sambamurthy, V.; Zmud, R.W. The assimilation of knowledge platforms in organizations: An empirical investigation. Organ. Sci. 2001, 12, 117-135. [CrossRef]

81. Hayes, A.F.; Preacher, K.J. Statistical mediation analysis with a multicategorical independent variable. $B r$. J. Math. Stat. Psychol. 2014, 67, 451-470. [CrossRef] [PubMed]

82. Berghman, M.; Hekkert, P. Towards a unified model of aesthetic pleasure in design. New Ideas Psychol. 2017, 47, 136-144. [CrossRef]

83. Blijlevens, J.; Thurgood, C.; Hekkert, P.; Chen, L.-L.; Leder, H.; Whitfield, T. The Aesthetic Pleasure in Design Scale: The development of a scale to measure aesthetic pleasure for designed artifacts. Psychol. Aesthet. Creat. Arts 2017, 11, 86. [CrossRef]

84. Chapman, J. Emotionally Durable Design: Sustaining Relationships Between Users and Domestic Electronic Products. Ph.D. Thesis, University of Brighton, Brighton, UK, 2008.

85. Chapman, J. Emotionally Durable Design: Objects, Experiences and Empathy; Routledge: London, UK, 2015.

86. Niinimäki, K.; Koskinen, I. I love this dress, it makes me feel beautiful! Empathic knowledge in sustainable design. Des. J. 2011, 14, 165-186. [CrossRef]

(C) 2019 by the authors. Licensee MDPI, Basel, Switzerland. This article is an open access article distributed under the terms and conditions of the Creative Commons Attribution (CC BY) license (http://creativecommons.org/licenses/by/4.0/). 